\title{
Geographical variations of early age sexual initiation among reproductive-age women in Ethiopia: evidence from EDHS 2016
}

\author{
Araya Mesfin Nigatu*, Abraham Yeneneh Birhanu and Berhanu Fikadie Endehabtu
}

\begin{abstract}
Background: The early age of sexual initiation contribute a lot for various risks such as mistimed pregnancy followed by insecure termination, developing fistula and contracting sexually transmitted infections which are currently the major public health concerns for low-income countries. Therefore, the purpose of this study was to detect spatial clusters and identify factors associated with an early age sexual initiation of women in the reproductive age group.

Methods: We used a population-based nationwide representative Ethiopian Demographic and Health Survey (EDHS) 2016 data.. A total of 12,033 respondents of reproductive age (15-49 years) women who had at least one event of sexual intercourse was retrieved and included for the analysis. Spatial cluster detection and autocorrelation analysis were also done to explore the patterns of early age sexual initiation.

Results: The median age at first sexual intercourse among respondents was $16( \pm 3.3)$ years and more than half (66.2\%) had their first sexual intercourse before the age of 18 years. The spatial variations of the age of sexual initiation was nonrandom and clustered with a Moran's $I=0.413$ ( $P$-value $<0.001)$. In addition, five significant spatial clusters were also identified. Moreover, the probability of starting sex at an earlier age was associated with the respondent's residence, marital status, educational attainment and wealth index.

Conclusion: This study found a higher proportion of an early age sexual initiation of women. Respondent's residence, marital status, educational attainment and wealth index were significantly associated with early sexual initiation. The SaTScan analysis identified five statistical significant spatial clusters which indicate that there were geographical variations. Therefore, integrated interventions focusing on the identified high spot clustered areas are recommended to reduce early age sexual initiation.
\end{abstract}

Keywords: Early sexual initiation, Geographical variations, Ethiopia

\footnotetext{
* Correspondence: hitdt2005@gmail.com

Department of Health Informatics, Institute of Public Health, University of

Gondar, P.O.Box 196, Gondar, Ethiopia

(c) The Author(s). 2020 Open Access This article is licensed under a Creative Commons Attribution 4.0 International License, which permits use, sharing, adaptation, distribution and reproduction in any medium or format, as long as you give appropriate credit to the original author(s) and the source, provide a link to the Creative Commons licence, and indicate if changes were made. The images or other third party material in this article are included in the article's Creative Commons licence, unless indicated otherwise in a credit line to the material. If material is not included in the article's Creative Commons licence and your intended use is not permitted by statutory regulation or exceeds the permitted use, you will need to obtain permission directly from the copyright holder. To view a copy of this licence, visit http://creativecommons.org/licenses/by/4.0/. The Creative Commons Public Domain Dedication waiver (http://creativecommons.org/publicdomain/zero/1.0/) applies to the data made available in this article, unless otherwise stated in a credit line to the data.
} 


\section{Background}

According to World Health Organization (WHO) report, annual number of maternal deaths and life time risk had showed significant improvement. Maternal death declined by $43 \%$ and lifetime risk improved from one in 73 to one in 180 [1]. However, developing regions still account nearly $99 \%$ of the global maternal deaths in which sub-Saharan Africa alone accounts for roughly $66 \%$, followed by Southern Asia 22\% [1]. From 20 million unsafe abortions done worldwide, 68,000 of maternal deaths were reported; from which teenage girls account for $14 \%$ [2].

Globally, 1.2 billion worldwide population are adolescents aged from 10 to 19 years; more than 1.1 million adolescent groups died of preventable causes related to pregnancy and childbirth complications which is the leading cause of death for 15-19 year's old age groups of girls [3]. Among adolescents with age less than 17 years; $30 \%$ of them have had sex and 252,000 pregnancies occur annually [4].

In Ethiopia, there are nearly 6 million women who are within the age group of 15-19 accounting for $12 \%$ of the total female population with extremely limited media access (26\% report at least weekly exposure to radio, $18 \%$ of television and 9\% to newspapers); consequently, 39\% had first sex before age 18 and $28 \%$ of recent births to women younger than 20 were unplanned [5].

According to EDHS 2011 report, 62\% of women had sexual intercourse before the age of 18 years [6].

A number of findings pointed out that, early age of sexual initiation is currently a progressive important concern for sexually active young adolescents. Youngsters who started early age sexual intercourse developed more risk behaviors which would have the likelihood of having multiple sexual partner that could lead them to many negative health outcomes (such as: unwanted pregnancies, unsafe abortion, vaginal fistula, sexually transmitted infections) and substantial socio-economic burdens [6-9]. There are many factors (intrinsic and extrinsic) which enables women to be engaged in early sexual initiation such as; low awareness on how and when to use contraceptive methods, self-desire to experience sex, social fitness, economic challenges, chewing Khat, drinking alcohol, watching pornographic materials, being less in parents, media content and social/religious ceremonies have been playing a major role [6-9]. Many studies have been conducted by concentrating on the demographic, socioeconomic, obstetric factors and reasons of adolescents to be engaged in early sexual intercourse [8-10], whereas little is known, about the geographical variations related to the issue. Therefore, the purpose of this study was to examine geographical disparities, and to identify significant predictors of an early age sexual initiation among reproductive age women in Ethiopia.

\section{Methods}

\section{Study design and setting}

A cross-sectional study was conducted to detect geographical clusters and determine factors associated with early age sexual initiation among reproductive-age women from EDHS 2016 data. The study was conducted in Ethiopia $\left(3^{\circ}-14^{\circ} \mathrm{N}\right.$ and $\left.33^{\circ}-48^{\circ} \mathrm{E}\right)$, located at the horn of Africa. Governmentally, the country is divided into nine regional states and two city administrations [11]. Each region is sub-divided into zones, districts, towns, and kebeles (the smallest administrative units).

\section{Data}

The data for this study were retrieved from the DHS program authorized database. The survey is usually conducted at five-year intervals in a country. The country has undertaken four consecutive DHS surveys in (2000, 2005, 2011 and 2016). The Ethiopian DHS was planned to have estimates from the nine regional states and two city administrations. Geographical location data (latitude and longitude coordinates) were also taken from selected enumeration areas. The survey data sets and location data were salvaged through the web page of the international demographic health survey program after subscription and being an approved user.

\section{Sampling technique and sampling size}

A stratified two-stage cluster sampling technique using a national representative population-based survey was employed. The data were collected from 645 enumeration areas (EAs) (202 urban and 443 rural areas) independently in each stratum of the two stages using systematic sampling with probability proportional to size. After applying the weighting technique, a total of 12,033 women of reproductive-age (15-49 years) who had at least one occurrence of sexual intercourse was retrieved and included for the analysis. Spatial cluster detection and autocorrelation analysis were also done to discover the patterns of early age sexual initiation (Fig. 1).

\section{Key variables and measurements Dependent variable}

The study variables were grouped into dependent and independent variables. The dependent variable was early age sexual initiation, categorized dichotomously as "Yes/ No" variable. Respondents who were engaged in sexual intercourse before the age of 18 were categorized as "Yes" and those who didn't as "No."

\section{Independent variables:}

- Socio-demographic variables: Current respondents age, residence, region, religion wealth index, 


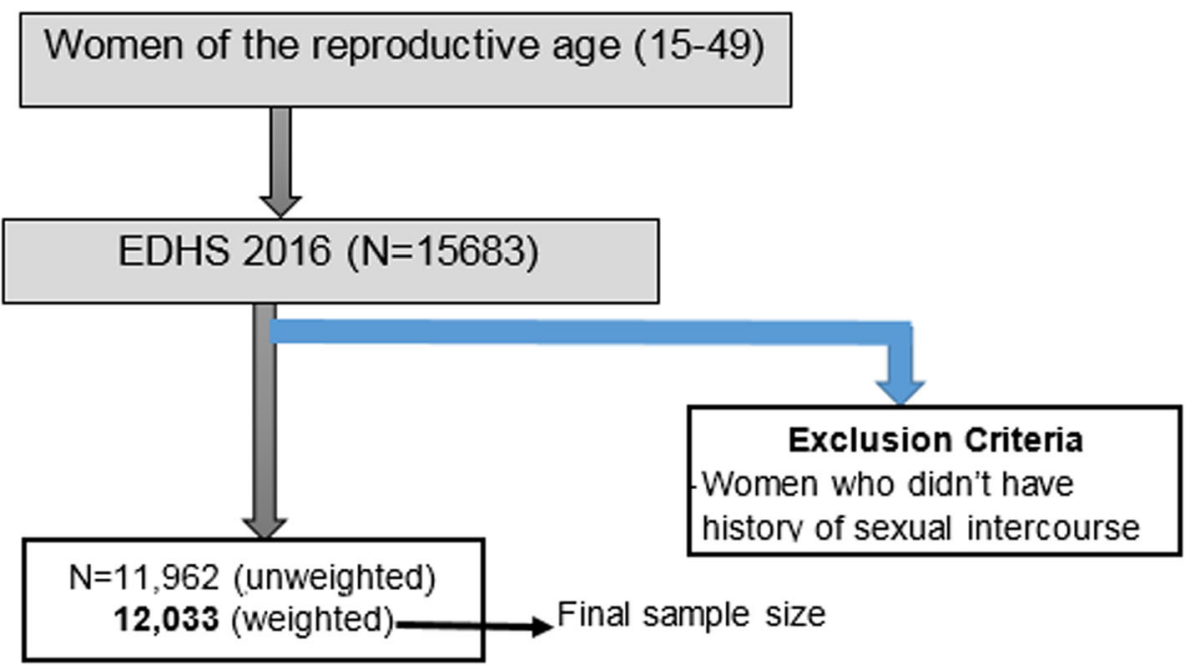

Fig. 1 The exclusion procedures to identify the final sample size in Ethiopia, EDHS 2016

women's education, working status, marital status, age at first marriage

- Sexual characteristics variables: Pregnancy, abortion, number of children ever born

\section{Data collection procedures and period}

Briefly, data were collected by visiting households and conducting face-to-face interviews to obtain information on demographic characteristics, socioeconomic status, sexual and reproductive history, starting from January 18, 2016, to June 27, 2016 [11].

\section{Operational definition}

Early age sexual initiation was defined as the experience of first intercourse before 18 years of age $[9,11]$.

\section{Statistical analyses}

\section{Descriptive and inferential analysis}

All variables in the DHS data for this analysis were given weight to adjust differences in the probability of selection and to adjust non-response in order to produce the proper representation using SPSS version 20. Descriptive statistics like frequencies, percentages, and measures of central tendency were computed. The bivariable analysis was also carried out to inspect the association between the dependent and each independent variables. All independent variables that were statistically significant at the bivariable model $<0.2 p$-values were included in the multivariable logistic regression model to prevent the possible effects of a confounder. Adjusted odds ratios with a 95\% confidence interval using the enter method were performed and variables with $\mathrm{p}$-value $<0.05$ in the multivariable model were considered as statistically significant.

\section{Spatial analysis}

Geographical Information System (ArcGIS version 10.4) software was used to visualize maps and analyze spatial statistics. Global and local scale spatial autocorrelation analysis were applied to explore the presence of clustering in the area and to detect the geographical location of clusters of the early age sexual initiation. The Moran's I index is the correlation coefficient, which measures the degree of association between a single variable with itself at different points in space as a function of the distance between points. The global Moran's I statistic was used to measure the geographical clustering over the nation; whereas local Moran's I statistic is used for constructing a localized measure of autocorrelation [12].

\section{Spatial autocorrelation analysis}

According to Tobler's first law of geography, "everything is related to everything else, but near things are more related than distant things $[13,14]$." The spatial autocorrelation (Global Moran's I) statistic measures were used to evaluate whether the case patterns are dispersed, clustered or randomly distributed in the study area in which its values range from -1 to 1 where Moran's I values close to -1 indicate perfect negative spatial autocorrelation (case dispersed), whereas Moran's I close to 1 means positive spatial (case clustered) and Moran's I zero implies perfect spatial randomness [15].

Anselin Local Moran's I was used to investigating the existence of local level cluster locations of early sexual initiation and Moran's I measure whether there were 
positively correlated (high-high and low-low) clusters or negatively correlated (high-low and low-high) clusters which are called outliers [16].

\section{Hot spot analysis (Getis-Ord Gi* statistic)}

The hot spot analysis tool calculates the Getis-Ord Gi* statistic that produces z-scores and $p$-values at a confidence level less than 0.05 which tell us where features with either high or low values cluster detected were statistically significant or not. Z-scores were used to assess the statistical difference of geographic clustering of early sexual initiation. A high (positive) z-score and small $p$-value of a feature indicate a significant hot spot whereas a low (negative) $\mathrm{z}$-score with a small pvalue indicates a significant cold spot; the higher or lower the z-scores, the more stronger the clustering, and a z-score near zero means no spatial clustering [17].

\section{Spatial interpolation}

Spatial interpolation technique was applied to predict values at unknown (non-sampled) locations using values at the measured (sampled) locations [18, 19]. Kriging spatial interpolation method was applied for predictions and produce smooth surfaces of the early age of sexual initiation.

\section{Cluster detection and spatial scan statistical analysis}

The spatial Scan statistical method is widely recommended since it performs very well in detecting local clusters [20]. It tests the presence of statistically significant spatial hotspots or clusters of early sexual initiation using Kuldorff's SaTScan version 9.4 software. It uses a scanning window that moves across a study area; women who started sexual intercourse before the age of 18 were considered as cases and those the age group of 18 and above as controls to fit the Bernoulli model $[12,21]$.

Spatial cluster size $<25 \%$ of the population was used, as a higher boundary, which allowed both small and large clusters to be detected and ignored clusters that contained more than the maximum boundary. For each potential cluster, a likelihood ratio test statistic was used to determine if the number of observed early age initiation of sexual intercourse within the potential cluster was significantly higher than expected or not. The primary and secondary clusters were identified and assigned $p$-values and ranked based on their log likelihood ratio test, on the basis of 999 Monte Carlo replications [12, 21].

\section{Ethical consideration}

This study was based on an analysis of existing survey data with all identifier information that can be linked to particular individuals were removed. Written consent
Table 1 Socio-demographic characteristics of respondents, EDHS 2016 (weighted sample, $n=12033$ )

\begin{tabular}{llll}
\hline Variables & \multicolumn{2}{l}{ Residence } & Total \\
\cline { 2 - 3 } & Urban $\mathrm{n}(\%)$ & Rural $\mathrm{n}(\%)$ & \\
\hline Current age in years & & & \\
$15-24$ & $496(17.4)$ & $2366(82.6)$ & $2865(23.8)$ \\
$25-34$ & $1067(21.4)$ & $3911(78.6)$ & $4978(41.4)$ \\
$\geq 35$ & $766(18.3)$ & $3424(81.7)$ & $4190(34.8)$
\end{tabular}

Mean \pm SD $(30.74 \pm 8.39$

Highest educational level

$\begin{array}{llll}\text { No education } & 519(7.3) & 6576(92.7) & 7095(59.0) \\ \text { Primary } & 772(22.1) & 2727(77.9) & 3499(29.1) \\ \text { Secondary } & 552(63.7) & 315(36.3) & 867(7.2) \\ \text { Higher } & 489(85.3) & 84(14.7) & 573(4.7) \\ \text { Region } & & & \\ \text { Tigray } & 198(22.6) & 677(77.4) & 875(7.3) \\ \text { Afar } & 28(25.7) & 81(74.3) & 109(0.9) \\ \text { Amhara } & 519(17.4) & 2459(82.6) & 2978(24.8) \\ \text { Oromia } & 575(12.7) & 3946(87.3) & 4521(37.6) \\ \text { Somali } & 61(17) & 297(83.0) & 358(3.0) \\ \text { Benshagul gumuz } & 19(14.8) & 109(85.2) & 128(1.1) \\ \text { SNNPR } & 282(12.0) & 2074(88.0) & 2356(19.6) \\ \text { Gambela } & 17(45.9) & 20(54.1) & 37(0.33) \\ \text { Hararai } & 16(53.3) & 14(46.7) & 30(0.2) \\ \text { Addis Ababa } & 572(100) & 0 & 572(4.8) \\ \text { Dire Dawa } & 45(67.2) & 22(32.8) & 672(0.6)\end{array}$

Religion

$\begin{array}{llll}\text { Orthodox Christian } & 1416(27) & 3819(73) & 5235(43.5) \\ \text { Muslim } & 462(11.7) & 3483(88.3) & 3945(32.8) \\ \text { Protestant } & 431(16.7) & 2149(83.3) & 2580(21.4) \\ \text { Others } & 24(8.7) & 251(91.3) & 275(2.3)\end{array}$

Wealth Index

$\begin{array}{llll}\text { Poorest } & 64(2.8) & 2190(97.2) & 2254(18.7)\end{array}$

$\begin{array}{llll}\text { Poorer } & 22(1.0) & 2291(99.0) & 2313(19.2)\end{array}$

Middle $\quad 35(1.5) \quad 2318(98.5) \quad 2353(19.6)$

Richer $\quad 87(3.8) \quad 2210(96.2) \quad 2297(19.1)$

$\begin{array}{llll}\text { Richest } & 2133(75.4) & 693(24.6) & 2816(23.4)\end{array}$

Respondent Occupation

\begin{tabular}{llll} 
Not working & $765(13.2)$ & $5049(86.8)$ & $5814(48.3)$ \\
Working & $1567(25.2)$ & $4652(74.8)$ & $6219(51.7)$ \\
$\begin{array}{l}\text { Marital status } \\
\text { Single }\end{array}$ & $233(58.1)$ & $168(41.9)$ & $401(3.3)$ \\
Married & $1655(16.2)$ & $8562(83.8)$ & $10,217(84.9)$ \\
Widowed & $123(28.7)$ & $306(71.3)$ & $429(3.6)$ \\
Divorced & $1250(33.1)$ & $506(66.9)$ & $756(6.3)$ \\
Separated & $71(30.7)$ & $160(69.3)$ & $231(1.9)$ \\
\hline
\end{tabular}




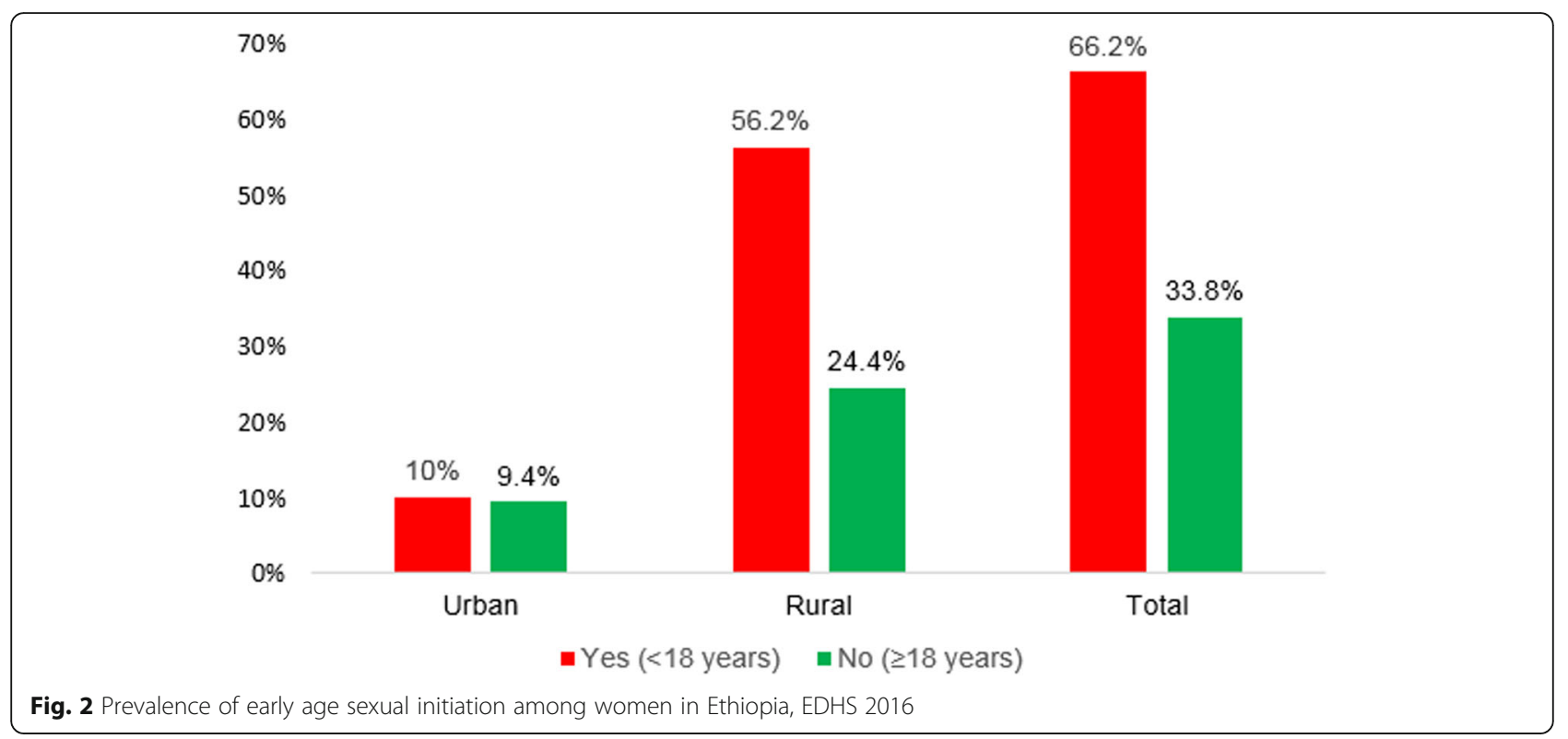

was obtained from the Measure DHS International Program, which authorized the datasets.

\section{Results}

\section{Socio-demographic characteristics}

From the total 12,033 women who participated in the study, a higher number of participants 37.6 and $24.8 \%$ were from Oromia and Amhara regions respectively. Four thousand nine hundred seventy-eight (41.4\%) of respondents' age ranges from 25 to 34 years and the mean age of the respondents was 30.9 years $(\mathrm{SD} \pm 8.3)$. Of the total respondents, 5235 (43.5\%) were Orthodox Christians followed by Muslim 3945 (32.8\%) by religion. More than half 7095 (59\%) of women didn't have any formal education from which rural residence constitute the major share of 6576 (92.8\%). Most of the respondents $(84.9 \%)$ were married. Slightly more than half of the respondents 6219 (51.7\%) had some jobs for pay (Table 1).

\section{Sexual intercourse characteristics of study participants}

After weighing the sample, the proportion of early sexual initiation of the respondents was $66.2 \%$ (95\% CI: 65.35 , $67.05 \%$ ) (Fig. 2). The median age of first sexual intercourse before the age of 18 was 16 years $( \pm 3.3)$ year. The age difference of respondents for their first sexual intercourse ranges from 8 years to 35 years. Among the respondents $(n=10,586)$ who gave birth, $4449(42 \%)$ of them were before the age of 18 and rural area women took the major share of the first birth proportion 3833 (86.2\%) and 2106 (94.4\%) of rural areas women have had more than seven children. Regarding their current pregnancy status, $1235(10.3 \%)$ of them checked and were sure about their pregnancy status (Table 2).

\section{Geographic variation and spatial clustering of early age sexual initiation}

In this study, geographical variation across regions for the early age of sexual initiation was observed. The spatial patterns of early sexual initiation of reproductiveage women were found to be non-random. The Global

Table 2 Sexual characteristics of reproductive-age women respondents, EDHS 2016 (weighted sample, $n=12033$ )

\begin{tabular}{|c|c|c|c|}
\hline \multirow[t]{2}{*}{ Variable } & \multicolumn{2}{|l|}{ Residence } & \multirow[t]{2}{*}{ Total n (\%) } \\
\hline & Urban n (\%) & Rural n (\%) & \\
\hline \multicolumn{4}{|c|}{ Age at first birth $(n=10,586)$} \\
\hline$<18$ years & $616(13.8)$ & $3833(86.2)$ & $4449(42)$ \\
\hline $18-24$ years & $921(17.2)$ & $4447(82.8)$ & $5368(50.7)$ \\
\hline$\geq 25$ years & $231(30.1)$ & $538(69.9)$ & $770(7.3)$ \\
\hline \multicolumn{4}{|c|}{ Number of children ever born } \\
\hline No child & $563(38.9)$ & $884(61.1)$ & $1447(12)$ \\
\hline 1-3 children & $1242(25.2)$ & $3679(74.8)$ & $4921(41)$ \\
\hline 4-6 children & $402(11.7)$ & $3033(88.3)$ & $3435(28.5)$ \\
\hline$\geq 7$ children & $124(5.6)$ & $2106(94.4)$ & $2230(18.5)$ \\
\hline \multicolumn{4}{|c|}{ Currently pregnant } \\
\hline No or unsure & $2171(19.9)$ & $8727(80.1)$ & $10,898(90.6)$ \\
\hline Yes & $161(14.2)$ & $974(85.8)$ & $1135(9.4)$ \\
\hline \multicolumn{4}{|c|}{ Ever terminated pregnancy } \\
\hline No & $2073(119.2)$ & $8725(80.8)$ & $10,799(89.7)$ \\
\hline Yes & $259(21)$ & $976(79)$ & $1235(10.3)$ \\
\hline
\end{tabular}




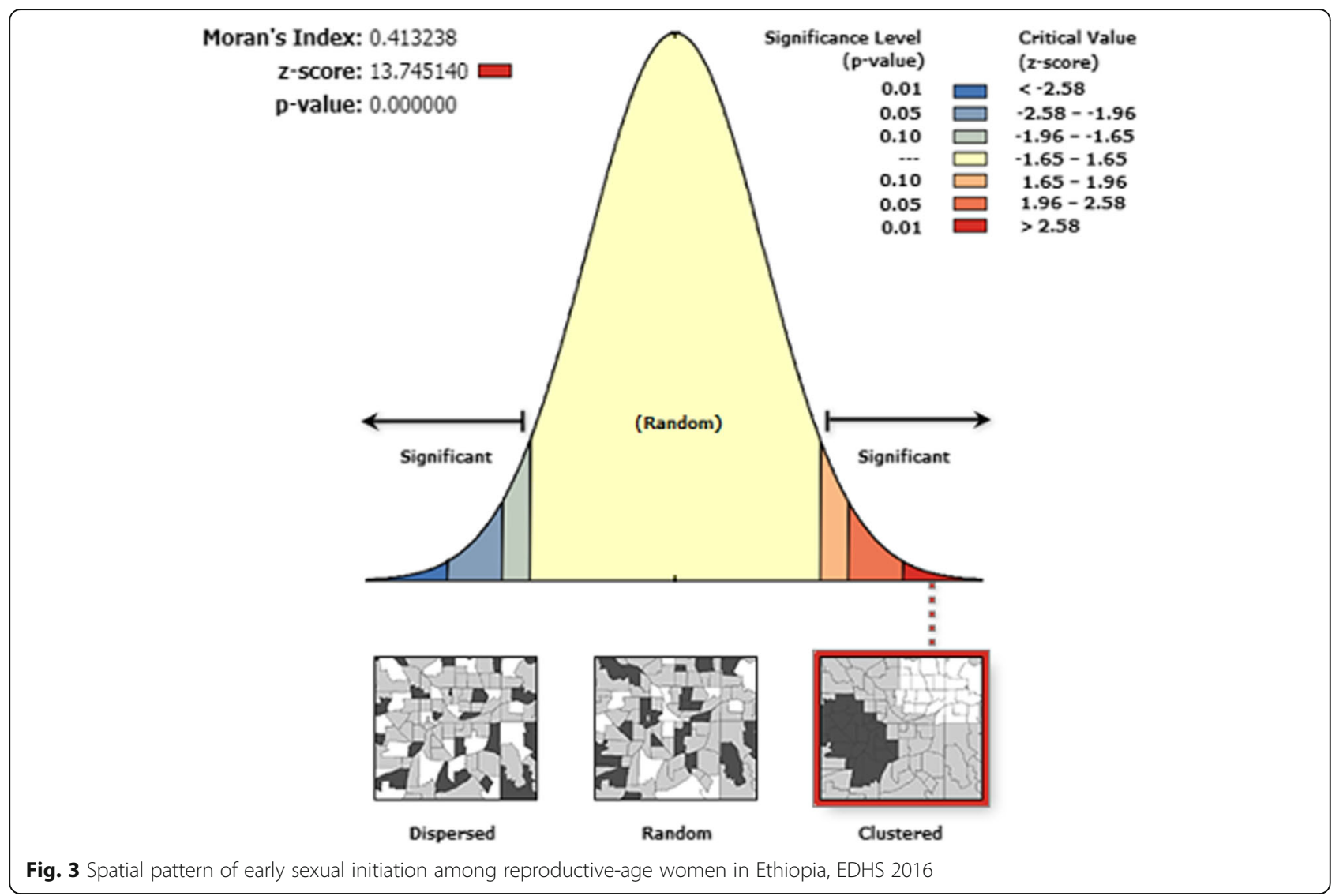

Moran's I values $(\mathrm{I}=0.41)$ indicated that there was significant clustering (99\% confidence, $P<0.001$ ) of early age sexual initiation in the country as a whole (Fig. 3).

Cluster and outlier analysis was used to detect hot spot areas and outliers of early sexual initiation. Hot spots were detected in most parts of Amhara and Oromia, Southwest Tigray, and Eastern part of Southern Nations, Nationalities, and Peoples' Region (SNNPR) regions; whereas cold spots in Gambela, BenshangulGumuz, Dire Dawa, Harari and Addis Ababa regions. Similarly, outliers were also detected in Northwest Oromia, Addis Ababa, Harari and Dire Dawa (Fig. 4). In general, Getis-Ord $\mathrm{Gi}^{*}$ was employed to check whether the detected clusters were statistically significant or not. Based on the result, high positive hot spots (Z-Score: 2.97-7.69, $p$-value <0.001) were detected in most parts of Amhara and Oromia, Southern Afar, Northeastern SNNPR and Eastern Tigray regions; whereas high negative hotspots (Z-Score: -2.06 to -6.70 , p-value $<0.001$ ) were also detected Eastern Tigray, Central and Northern parts of Afar, Central and Northern parts of Gambela, Northern Somali, Central and Southern parts of Benshangul-Gumuz, Dire Dawa, Western Oromia, and Harari regions (Fig. 5).

\section{Spatial scan statistics result}

In this study, data were representative at the national, regional, and rural-urban levels and can be generalized to all women early age sexual initiation in Ethiopia. The Geographic information system (GIS) and SaTScan statistical tests detected similar and statistically significant high-risk clusters/hotspots of early age sexual initiation. From the SaTScan output, we identified 14 spatial clusters, from which the first five of them were statistically significant at $P$-value $<0.05$.

The primary cluster, the blue color ring spatial window was typically located at the Northern part of the country which encompasses most parts of Amhara, Northeast Benshangul-Gumuz, Southern Tigray and Northern parts of Oromia regions. This spatial window was centered at $11.699828 \mathrm{~N}, 37.313043 \mathrm{E}$ with a 256.31 $\mathrm{km}$ radius. In addition, the remaining two spatial windows with red and pink colors were secondary clusters. The red color spatial window covers Northeastern Oromia, Western Dire Dawa, and Southern Afar whereas the pink color spatial window embraces Southern Oromia and Southwest Somali regions. These spatial windows were centered at $8.888553 \mathrm{~N}, 40.744565 \mathrm{E}$ with $63.62 \mathrm{~km}$ radius and $5.203234 \mathrm{~N}, 40.019732 \mathrm{E}$ with 

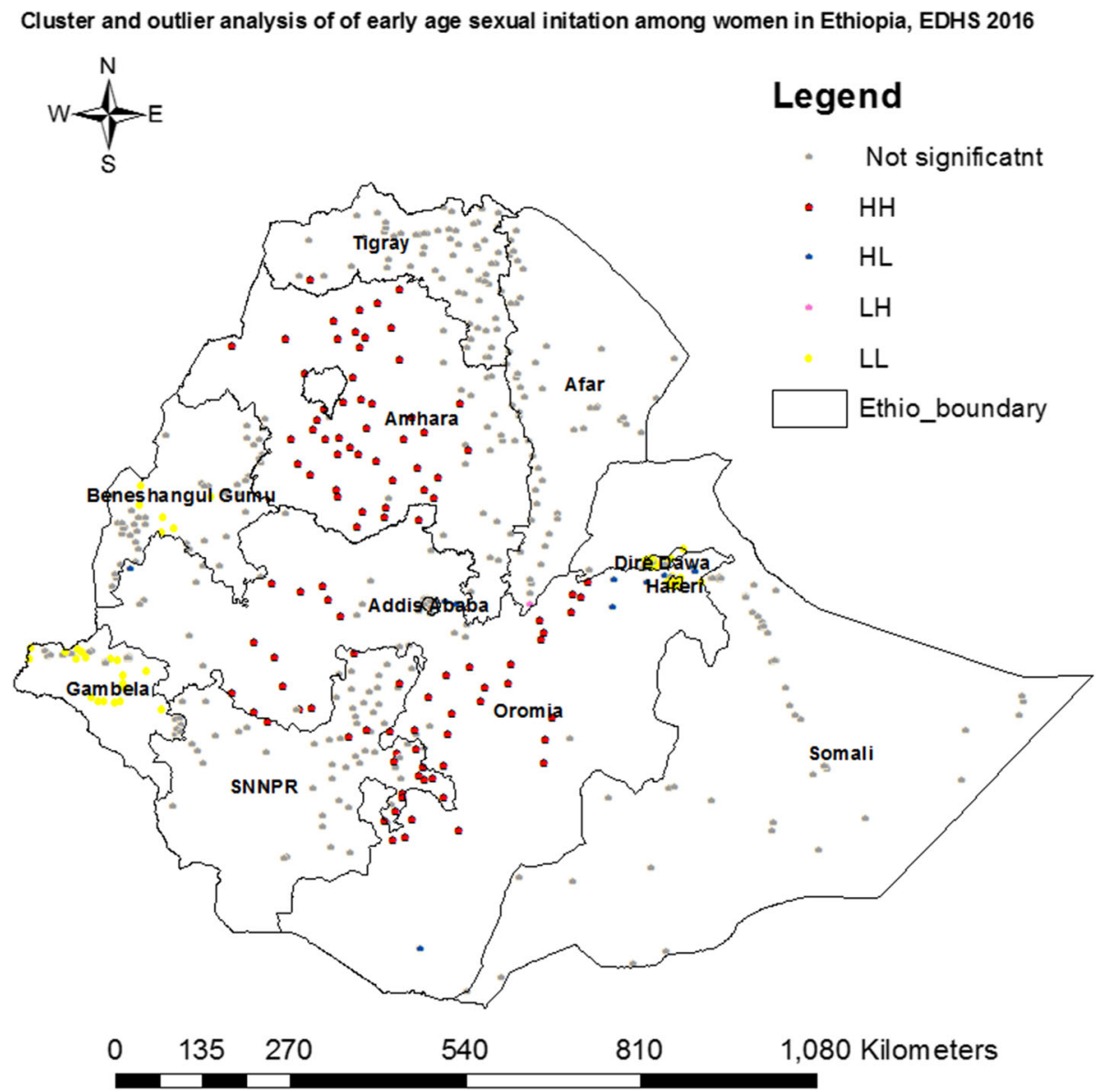

Fig. 4 Cluster outlier identification of early age sexual initiation in Ethiopia, EDHS 2016

$116.80 \mathrm{~km}$ radius respectively. However, the third and the fourth spatial windows of the detected secondary cluster were not plotted, because the clusters were detected only a single location identification (ID) (Table 3, Fig. 6).

\section{Spatial interpolation}

The kriging prediction map with dark red color told us that Eastern, Western and Southern parts of Oromia, Northwest and Southern parts of Amhara regions of the nation were predicted as risk areas for early age sexual initiation (Fig. 7).

\section{Factors associated with early sexual initiation among reproductive-age women}

Early sexual initiation in Ethiopian women varied under the influence of various factors. After fitting the multivariable logistic regression, four variables were identified to be significantly associated with early age sexual initiation.

Being rural residence was found to be 1.31 times more likely to initiate sexual intercourse before the age of 18 years than urban women $(\mathrm{AOR}=1.31,95 \% \mathrm{CI}$ : 1.11 , 1.55). Married (AOR $=1.71,95 \% \mathrm{CI}: 1.36,2.15)$, widowed $(\mathrm{AOR}=2.63,95 \% \mathrm{CI}: 1.92,3.61)$ and divorced $(\mathrm{AOR}=$ 2.32, 95\% CI: 1.77, 3.06) women were 1.71, 2.63 and 2.32 times more likely to experience early sexual initiation as compared to single women respectively. Women with no education $(\mathrm{AOR}=9.58,95 \% \mathrm{CI}: 7.60,12.08)$, primary $(\mathrm{AOR}=6.59,95 \% \mathrm{CI}: 5.25,8.27)$ and secondary $(\mathrm{AOR}=$ 2.51, 95\% CI: 1.96, 3.21) had 9.58, 6.59 and 2.51 times higher odds of having experienced early age sexual initiation as compared to higher educational level women respectively.

Poorer $(\mathrm{AOR}=1.28,95 \% \mathrm{CI}: 1.12,1.46)$ and richest $(\mathrm{AOR}=1.46,95 \% \mathrm{CI}: 1.23,1.74)$ were 1.28 and 1.46 times more likely to experience early sexual initiation when compared to poorest women respectively (Table 4).

\section{Discussion}

In this study, the prevalence and spatial distribution of early age of sexual intercourse was assessed. The 


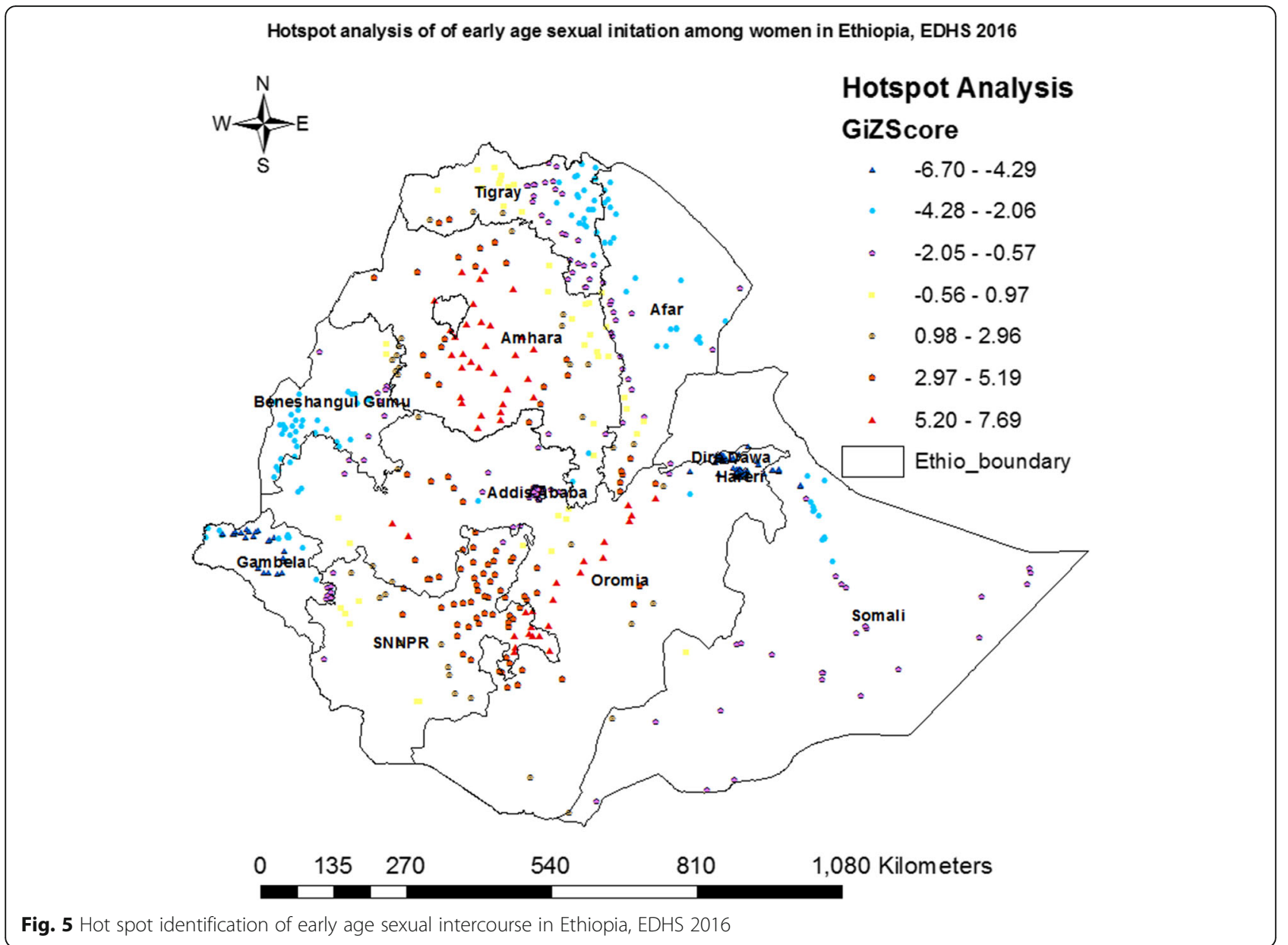

number of early sexual initiation cases per cluster was found to vary geographically) Five statistical significant spatial clusters $(P$-value $<0.01)$ were also detected across the regions of the country Findings from this study showed that, the prevalence of early sexual initiation among reproductive-age women was $66.2 \%$ (95\% CI: 65.4, 67.1\%). The result of this study was lower than a study conducted in South Africa 70.8\% [22]. The difference, higher in South Africa may be explained by the study participant's composition (African, White, and Asian). In addition, there was also higher proportion of urban residence $(76.2 \%)$ respondents who participated in the study compared to the current study $19.4 \%$ which gave chance of getting access to education which might help them to increase their awareness of the negative consequences of early age sexual intercourse.

However, the current study proportion was higher than different pocket study findings conducted in Ethiopia (29\% [11], 59.5\% [23], 56.9\% [24], 53.7\% [10]), Nigeria 28.7\% [25], China 10.7\% [7] and Tanzania 57.8\% [26]. The possible explanation for this might be due to the advancement of technology that enhances watching

Table 3 Significant clusters of early age sexual initiation among reproductive age women, EDHS 2016

\begin{tabular}{lllllll}
\hline Type of cluster & Total \# of population & Total \# of cases & RR & Cases (\%) & LLR & Coordinates/Radius \\
\hline Most likely cluster $^{\mathrm{a}}$ & 2866 & 2305 & 1.3 & 80.4 & 175.06 & $(11.699828 \mathrm{~N}, 37.313043 \mathrm{E}) / 256.31 \mathrm{~km}$ \\
Secondary cluster $^{\mathrm{b}}$ & 620 & 516 & 1.27 & 83.2 & 45.75 & $(8.888553 \mathrm{~N}, 40.744565 \mathrm{E}) / 63.62 \mathrm{~km}$ \\
Secondary cluster $^{\mathrm{b}}$ & 82 & 31 & 1.43 & 95.1 & 20.27 & $(5.203234 \mathrm{~N}, 40.019732 \mathrm{E}) / 116 \mathrm{~km}$ \\
Secondary cluster $^{\mathrm{b}}$ & 33 & 33 & 1.5 & 100 & 13.46 & $(7.146476 \mathrm{~N}, 37.651926 \mathrm{E}) / 0 \mathrm{~km}$ \\
Secondary cluster $^{\mathrm{b}}$ & 37 & 36 & 1.46 & 97.3 & 11.18 & $(7.747932 \mathrm{~N}, 36.027719 \mathrm{E}) / 0 \mathrm{~km}$ \\
\hline
\end{tabular}

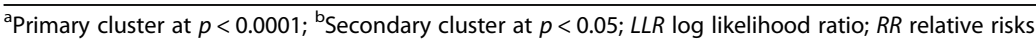




\section{Primary and secondary clusters of early sexual initiation among reproductive age women in Ethiopia, EDHS 2016}

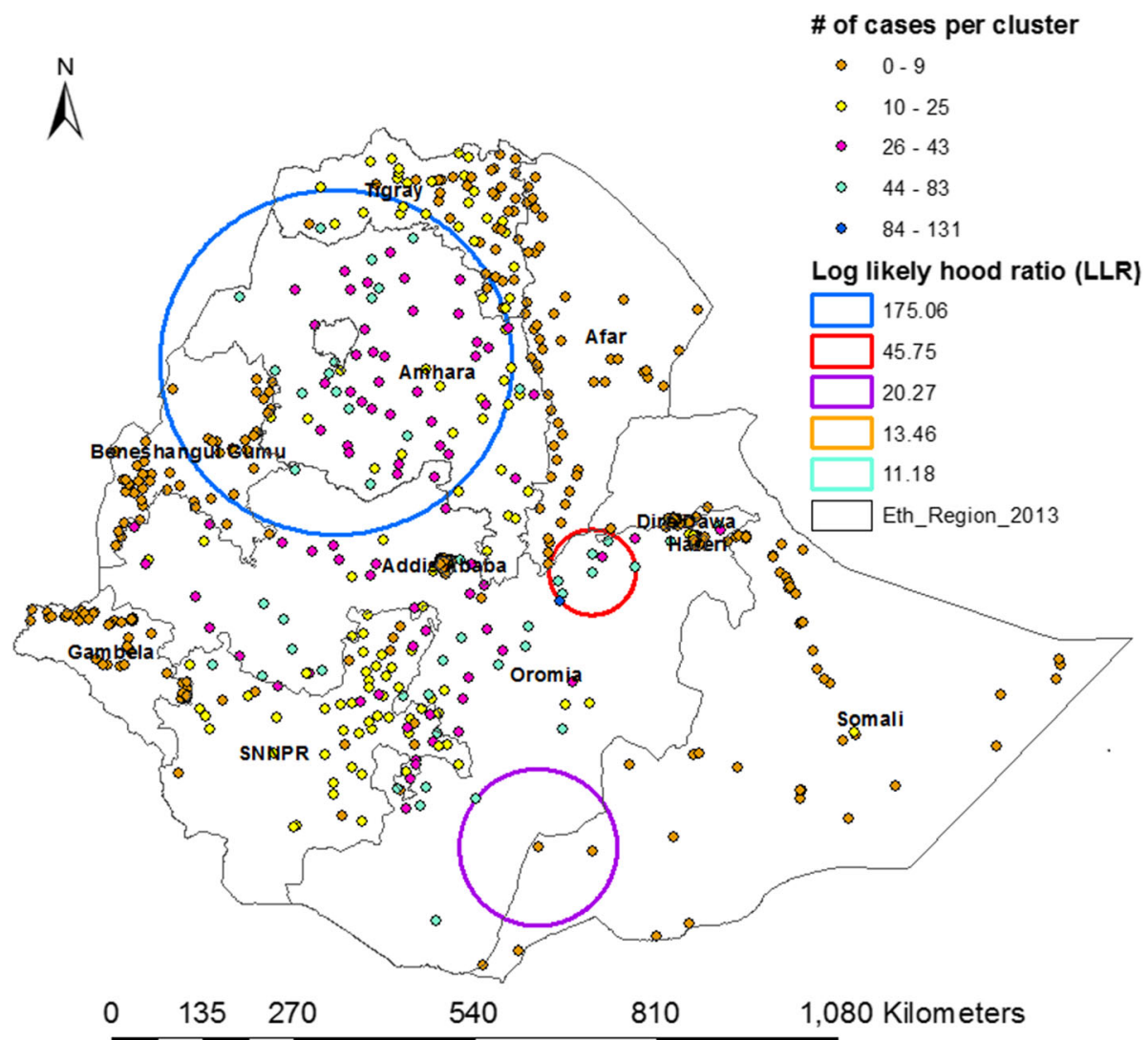

Fig. 6 Primary and secondary clusters of early sexual initiation among reproductive-age women in Ethiopia, EDHS 2016

pornographic videos and substance use which may increase the probability of taking part in early sexual intercourse activities.

Our study recognized that place of residence, household wealth index, educational attainment, and marital status as statistical significant contributing factors for early sexual initiation in the multivariable logistic regression analysis. From the 1136 (9.4\%) currently pregnant and 1235 (10.3\%) ever had a history of terminating pregnancy respondents; $702(61.8 \%)$ and $867(70.2 \%)$ of them started early age sexual intercourse respectively although they were not statistically significant in the multivariable logistic regression analysis (Table 4).

Rural residence respondents were 1.31 times more likely than urban area women for early sexual initiation $[\mathrm{AOR}=1.31,95 \% \mathrm{CI}:(1.11,1.55)]$. This finding was in line with pocket studies conducted in Ethiopia [8,9]. The possible explanation for this could be low awareness of the community on reproductive health issues and the bad consequence of early marriage for rural adolescents.
Another significant association was also maintained between marital status and early sexual initiation. Being widowed $[\mathrm{AOR}=2.63,95 \% \mathrm{CI}:(1.92,3.61)]$, divorced $[\mathrm{AOR}=2.32,95 \% \mathrm{CI}:(1.77,3.06)]$ and married $[\mathrm{AOR}=$ 1.71, 95\% CI: $(1.36,2.15)]$ were $2.63,2.32$ and 1.71 times more likely to experience early sexual initiation when compared to never married respondents respectively. This finding is comparable to pocket studies done in Ethiopia [9, 10, 27]. The possible justification for this might be engaged in early marriage (before the age of 18 years) which is the potential scenario for women to be engaged in early age sexual intercourse activity. As indicated on the EDHS 2011 report, the median age of first marriage in the country was 17.1 years [11].

A strong statistical association was also held between education and early sexual initiation. Women with no education $[\mathrm{AOR}=9.58,95 \% \mathrm{CI}:(7.60-12.8)]$, primary $[\mathrm{AOR}=6.59, \quad 95 \%$ CI: $(5.25-8.27)]$ and secondary $[\mathrm{AOR}=2.51,95 \% \mathrm{CI}:(1.91-3.21)]$ had 9.58, 6.59 and 2.51 times higher odds of having experienced early age 


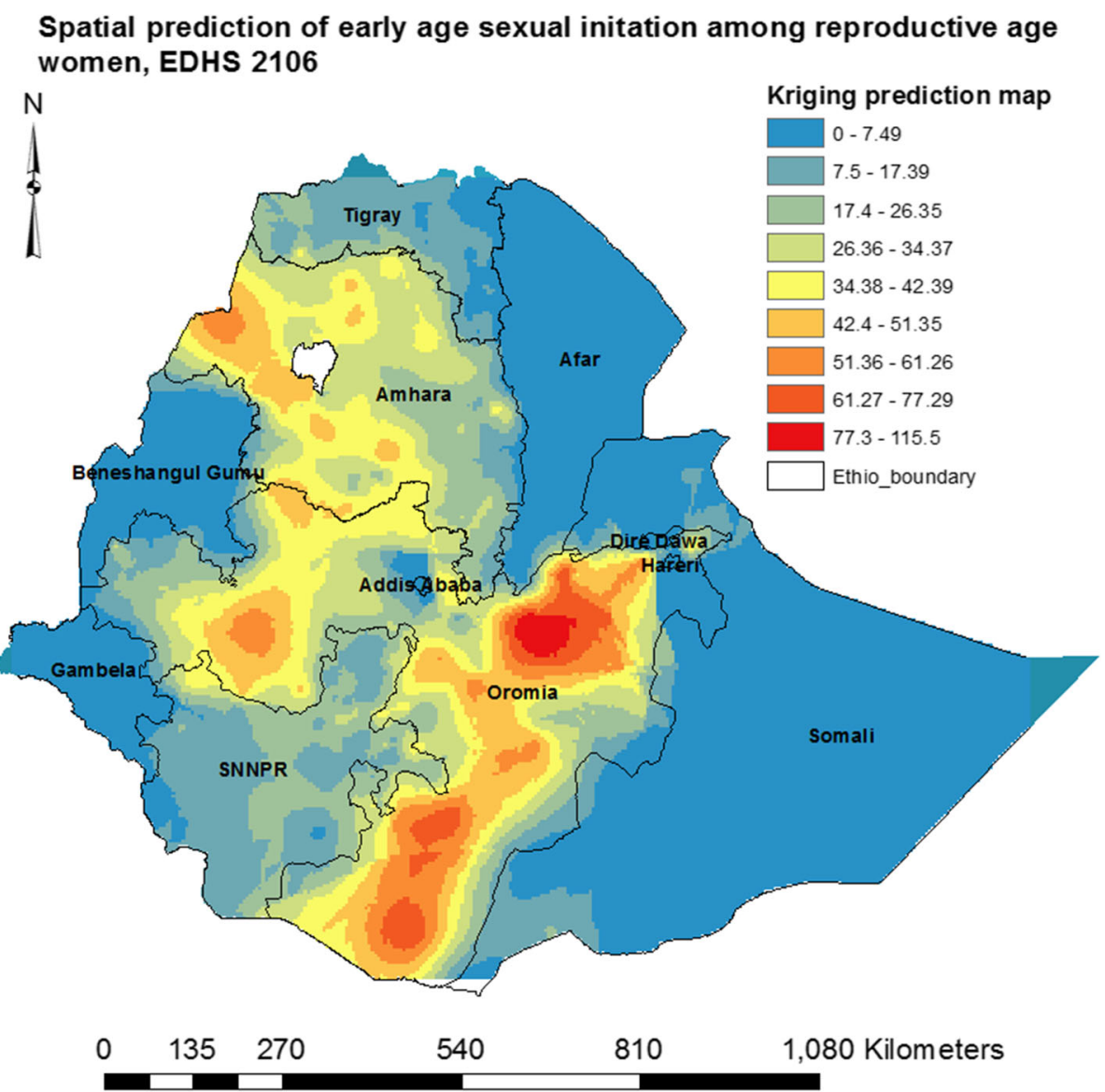

Fig. 7 Spatial prediction of early age sexual initiation among reproductive-age women in Ethiopia, EDHS 2016

sexual initiation as compared to women having higher educational level respectively. This finding is consistent with a study done in Ethiopia [9, 28, 29], Malawi [30], Kenya [29], South Africa [31] and Nigeria [32]. The possible explanation for this could be when women had better educational status, they will understand potential risks related with early age sexual intercourse and might protect themselves from being engaged.

Another statistical significant association was also identified between wealth index and early age sexual initiation. Poorer $[\mathrm{AOR}=1.28,95 \% \mathrm{CI}:(1.12-1.46)]$ and richest $[\mathrm{AOR}=1.46,95 \% \mathrm{CI}:(1.23,1.74)]$ were 1.28 and 1.46 times more likely to experience early sexual initiation as compared to the poorest women respectively. This finding is consistent with studies done in Kenya [29]. The probable reason for this could be an economic problem for poorer ones; economically poor respondents might be cheated by gift (either in cash or in-kind) which initiates them to be volunteer to take part. On the other hand richest respondents as they were capable of financial issues, they might frequently attend different pornographic films using different technological products which pushes them to be involved in early sexual intercourse.

The spatial pattern was non-random and hot spots areas were found in most parts of Amhara and Oromia, Southwest Tigray, and Eastern part of Southern Nations, Nationalities, and Peoples' Region (SNNPR) regions. On the other hand, hot spot areas were found in the regions where majority of the populations reside. The study shows that significant geographical variations in early age sexual initiation exists within Ethiopia. This study finding is consistent with studies conducted in Nigeria [33].

However, there were some limitations in this study. Sexual practice has private, intimate, and sensitive nature in the society, there might be an underreporting of some behaviors. Similarly, self-reporting of sexual behaviors could have introduced recall or social desirability bias. The cross-sectional nature of the data also prevents causality from being inferred between age of sexual initiation and significant predictors. In addition, respondents' data who didn't have files (longitude and latitude) 
Table 4 Factors associated with early age sexual initiation among reproductive-age women in Ethiopia, EDHS 2016 (weighted sample $n=12033$ )

\begin{tabular}{|c|c|c|c|c|}
\hline \multirow[t]{2}{*}{ Variables } & \multicolumn{2}{|c|}{ Early sexual initiation } & \multirow{2}{*}{$\begin{array}{l}\text { Crude OR } \\
(95 \% \mathrm{Cl})\end{array}$} & \multirow{2}{*}{$\begin{array}{l}\text { Adjusted OR } \\
(95 \% \mathrm{Cl})\end{array}$} \\
\hline & No (\%) & Yes (\%) & & \\
\hline \multicolumn{5}{|l|}{ Residence } \\
\hline Urban & $1138(28)$ & $1194(15)$ & Ref & Ref \\
\hline Rural & $2930(72)$ & $6771(85)$ & $2.20(2.01,2.42)$ & $1.31(1.11,1.55)^{a}$ \\
\hline \multicolumn{5}{|l|}{ Wealth Index } \\
\hline Poorest & $702(17.3)$ & $1552(19.4)$ & Ref & Ref \\
\hline Poorer & $627(15.4)$ & $1686(21.2)$ & $1.22(1.07,1.38)$ & $1.28(1.92,1.46)^{a}$ \\
\hline Middle & $716(17.6)$ & $1638(20.6)$ & $1.04(0.91,1.17)$ & $1.12(0.98,1.27)$ \\
\hline Richer & $760(18.7)$ & $1537(19.3)$ & $0.92(0.81,1.04)$ & $1.10(0.97,1.25)$ \\
\hline Richest & $1263(31.0)$ & $1552(19.5)$ & $0.56(0.49,0.62)$ & $1.46(1.23,1.74)^{a}$ \\
\hline \multicolumn{5}{|l|}{ Marital Status } \\
\hline Single & $251(6.2)$ & $149(1.9)$ & Ref & Ref \\
\hline Married & 3401 (83.6) & $6816(85.6)$ & $3.37(2.74,4.15)$ & $1.71(1.36,2.15)^{a}$ \\
\hline Widowed & $109(2.7)$ & $321(4.0)$ & $4.96(3.69,6.68)$ & $2.63(1.92,3.61)^{a}$ \\
\hline Divorced & $209(5.1)$ & $547(6.9)$ & $4.41(3.41,5.70)$ & $2.32(1.77,3.06)^{a}$ \\
\hline Separated & $98(2.4)$ & $132(1.7)$ & $2.25(1.62,3.13)$ & $1.31(0.92,1.86)$ \\
\hline \multicolumn{5}{|l|}{ Education } \\
\hline No education & $1889(46.4)$ & $5206(65.4)$ & $10.50(8.52,12.94)$ & $9.58(7.60,12.08)^{2}$ \\
\hline Primary & $1214(29.8)$ & $2286(28.7)$ & $7.2(5.79,8.88)$ & $6.59(5.25,8.27)^{a}$ \\
\hline Secondary & $512(12.6)$ & $354(4.4)$ & $2.64(2.07,3.36)$ & $2.51(1.96,3.21)^{a}$ \\
\hline Higher & $453(11.1)$ & $119(1.5)$ & Ref & Ref \\
\hline \multicolumn{5}{|c|}{ Currently pregnant } \\
\hline No or unsure & 3634 (89.3) & $7263(91.2)$ & Ref & Ref \\
\hline Yes & $434(10.7)$ & 702 (8.8) & $1.2(1.1,1.4)$ & $1.0(0.8,1.1)$ \\
\hline \multicolumn{5}{|c|}{ Ever had terminated } \\
\hline No & $3700(91.0)$ & $7098(89.1)$ & Ref & Ref \\
\hline Yes & $368(9.0)$ & 867 (10.9) & $1.2(1.1,1.4)$ & $1.1(0.9,1.2)$ \\
\hline
\end{tabular}

Hosmer-Lemeshow Goodnes of Fit Test $=0.89 ;$ Ref $=$ reference; ${ }^{a}=$ Significant

were excluded from the spatial analysis which could affect the overall result and the generalization we made as well.

Despite, SaTScan analysis can identify spatial clusters, but can't explain why the variations in the risks of the events of interest exist.

\section{Conclusion}

In general, the prevalence of early age sexual initiation among reproductive-age women was high. Residence, educational attainment, wealth index, and marital status were identified as statistically significant factors. A total of five significant clusters (most likely and secondary clusters) $(\mathrm{LLR}=175.06,45.75,20.27,13.46$ and 11.18, at $P$-value $<0.01)$ were detected in Amhara, Oromia, Somali, Tigray and Benshangul-Gumuz regions of the country. Therefore, identifying the hot spot areas for early sexual intercourse can help to design tailored innervations which can help to reduce maternal morbidity and mortality contributed by early sexual intercourse.

\section{Abbreviations \\ CSA: Central Statics Agency; EDHS: Ethiopia Demographic and Health Survey; GIS: Geographic Information System; GPS: Global Positioning System: LLR: Log Likelihood Ratio; OR: Odds Ratio; RR: Relative Risk; SNNPR: Southern Nations, Nationalities, and Peoples' Region}

\section{Acknowledgments}

The authors are glad to thank the Measure DHS International Program for granting access to the Ethiopia Demographic and Health Survey 2016 data.

\section{Authors' contributions}

AM designed the study, performed analysis and interpretation, and prepared the manuscript. AY designed the study, participated in the analysis and interpretation of the drafted manuscript. BF participated in the design of the study, assisted and revised the draft manuscript. All authors approved the final manuscript. 
Funding

Self-sponsored.

\section{Availability of data and materials}

The data in which the authors used to produce this manuscript are available and the authors are prepared to share our data on request recognizing the benefits of such transparency. Otherwise, the data-set can be accessed through www.dhsprogram.com after subscription and being an authorized user.

\section{Ethics approval and consent to participate}

Written consent was obtained from Measure DHS International Program which authorized the data-sets. All the data which was used in this study are publicly available, aggregated secondary data with not having any personal identifying information that can be linked to particular individuals, communities, or study participants. Confidentiality of data maintained anonymously.

\section{Consent for publication}

Not applicable.

\section{Competing interests}

The authors declare that they have no competing interests.

Received: 8 December 2019 Accepted: 18 March 2020 Published online: 01 June 2020

\section{References}

1. WHO U. UNFPA, World Bank Group and the United Nations Population Division. Trends in maternal mortality: 1990 to 2015. Geneva: Estimates by WHO, UNICEF. UNFPA, World Bank Group and the United Nations Population Division; 2015.

2. Unicef. Young people and family planning: Teenage pregnancy. Malaysia: UNICEF; 2008

3. Organization WH. Adolescents: health risks and solutions. 2018

4. Finer LB, Philbin JM. Sexual initiation, contraceptive use, and pregnancy among young adolescents. Pediatrics. 2013:131(5):886.

5. Federation IPP. Sexual and reproductive health of young women in Ethiopia; 2014

6. Campus D. Assessing factors influencing early sexual initiation among adolescents (13 to 19 years) in Ghana: A qualitative study; 2018.

7. Li J, Li S, Yan H, Xu D, Xiao H, Cao Y, et al. Early sex initiation and subsequent unsafe sexual behaviors and sex-related risks among female undergraduates in Wuhan, China. Asia Pac J Public Health. 2015;27(2_suppl): 21S-95.

8. Bizu D, Aderaw Z, Kassa GM. Assessment of early sexual initiation and associated factors among preparatory school students of FaggetaLekoma District, Awi zone, Northwest Ethiopia, 2015. Int J Clin Med. 2015:6(8):521.

9. Mazengia F, Worku A. Age at sexual initiation and factors associated with it among youths in North East Ethiopia. Ethiopian J Health Dev. 2009;23(2): 154-62.

10. Digafe TN. Determinants of sexual debut among high school girl students in Arsi Zone, Huruta town, Ethiopia. Epidemiol. 2017;7(3):2161-1165.

11. Demographic CE. Health Survey-2011. Addis Ababa, Ethiopia Calverton, Maryland: Central Statistical Agency and ICF International; 2012. p. 2016.

12. Kulldorff M. SaTScanTM user guide; 2006.

13. Legendre P. Spatial autocorrelation: trouble or new paradigm? Ecology. 1993;74(6):1659-73.

14. Tobler WR. A computer movie simulating urban growth in the Detroit region. Econ Geography. 1970;46(sup 1):234-40.

15. Zulu LC, Kalipeni E, Johannes E. Analyzing spatial clustering and the spatiotemporal nature and trends of HIV/AIDS prevalence using GIS: the case of Malawi, 1994-2010. BMC Infect Dis. 2014;14(1):285.

16. Getis A, Ord JK. Local spatial statistics: an overview. Spatial Anal. 1996;374: 261-77.

17. De Valck J, Broekx S, Liekens I, De Nocker L, Van Orshoven J, Vranken L. Contrasting collective preferences for outdoor recreation and substitutability of nature areas using hot spot mapping. Landsc Urban Plan. 2016;151:6478.

18. Krivoruchko K, Krause E. Concepts and Applications of Kriging. San Diego: ESRI International User Conference; 2011.
19. Santiago I. Fundamentos de ArcGIS versión 10.2. Puerto Rico: Tutorial de ejercicios; 2014.

20. Kulldorff M. A spatial scan statistic. Commun Stat Theory Methods. 1997; 26(6):1481-96.

21. Hjalmars U, Kulldorff M, Gustafsson G, Nagarwalla N. Childhood leukaemia in Sweden: using GIS and a spatial scan statistic for cluster detection. Stat Med. 1996;15(7-9):707-15.

22. Manzini N. Sexual initiation and childbearing among adolescent girls in KwaZulu Natal, South Africa. Reprod Health Matters. 2001:9(17):44-52.

23. Ayalew A, Abreha K, Shumey A, Berhane K. Magnitude and predictors of early sexual debut among high and preparatory school students in northern Ethiopia: a school-based Crosssectional study. J Health Educ Res Dev. 2015:3:1-8.

24. Tilahun M, Ayele G. Factors associated with age at first sexual initiation among youths in Gamo Gofa, south West Ethiopia: a cross sectional study. BMC Public Health. 2013;13(1):622.

25. Fatusi $\mathrm{AO}$, Blum RW. Predictors of early sexual initiation among a nationally representative sample of Nigerian adolescents. BMC Public Health. 2008;8(1): 136.

26. Mmbaga EJ, Leonard F, Leyna GH. Incidence and predictors of adolescent's early sexual debut after three decades of HIV interventions in Tanzania: a time to debut analysis. PLoS One. 2012:7(7):e41700.

27. Tadesse G, Yakob B. Risky sexual behaviors among female youth in Tiss Abay, a semi-urban area of the Amhara region, Ethiopia. PLoS One. 2015: 10(3):e0119050.

28. Nigatu DT, Seme A, Fituma S, Segni MT. Sexual initiation and associated factors among young women in west Shoa, ambo town, Ethiopia: a community-based cross-sectional study. BMC Womens Health. 2018;18(1):76.

29. Okigbo CC, Speizer IS. Determinants of sexual activity and pregnancy among unmarried young women in urban Kenya: a cross-sectional study. PLoS One. 2015:10(6):e0129286.

30. Glynn JR, Kayuni N, Floyd S, Banda E, Francis-Chizororo M, Tanton C, et al. Age at menarche, schooling, and sexual debut in northern Malawi. PLoS One. 2010;5(12):e15334.

31. Zuma K, Setswe G, Ketye Y, Mzolo T, Rehle T, Mbelle N. Age at sexual debut: a determinant of multiple partnership among south African youth. Afr J Reprod Health. 2010;14(2):47-54.

32. Aga S, Van Rossem R, Ankomah A. Community-level influences on early sexual initiation in Nigeria. San Diego: MEASURE Evaluation Working Paper Series; 2006.

33. Uthman OA. Geographical variations and contextual effects on age of initiation of sexual intercourse among women in Nigeria: a multilevel and spatial analysis. Int J Health Geogr. 2008;7(1):27.

\section{Publisher's Note}

Springer Nature remains neutral with regard to jurisdictional claims in published maps and institutional affiliations.

Ready to submit your research? Choose BMC and benefit from:

- fast, convenient online submission

- thorough peer review by experienced researchers in your field

- rapid publication on acceptance

- support for research data, including large and complex data types

- gold Open Access which fosters wider collaboration and increased citations

- maximum visibility for your research: over $100 \mathrm{M}$ website views per year

At BMC, research is always in progress.

Learn more biomedcentral.com/submission 